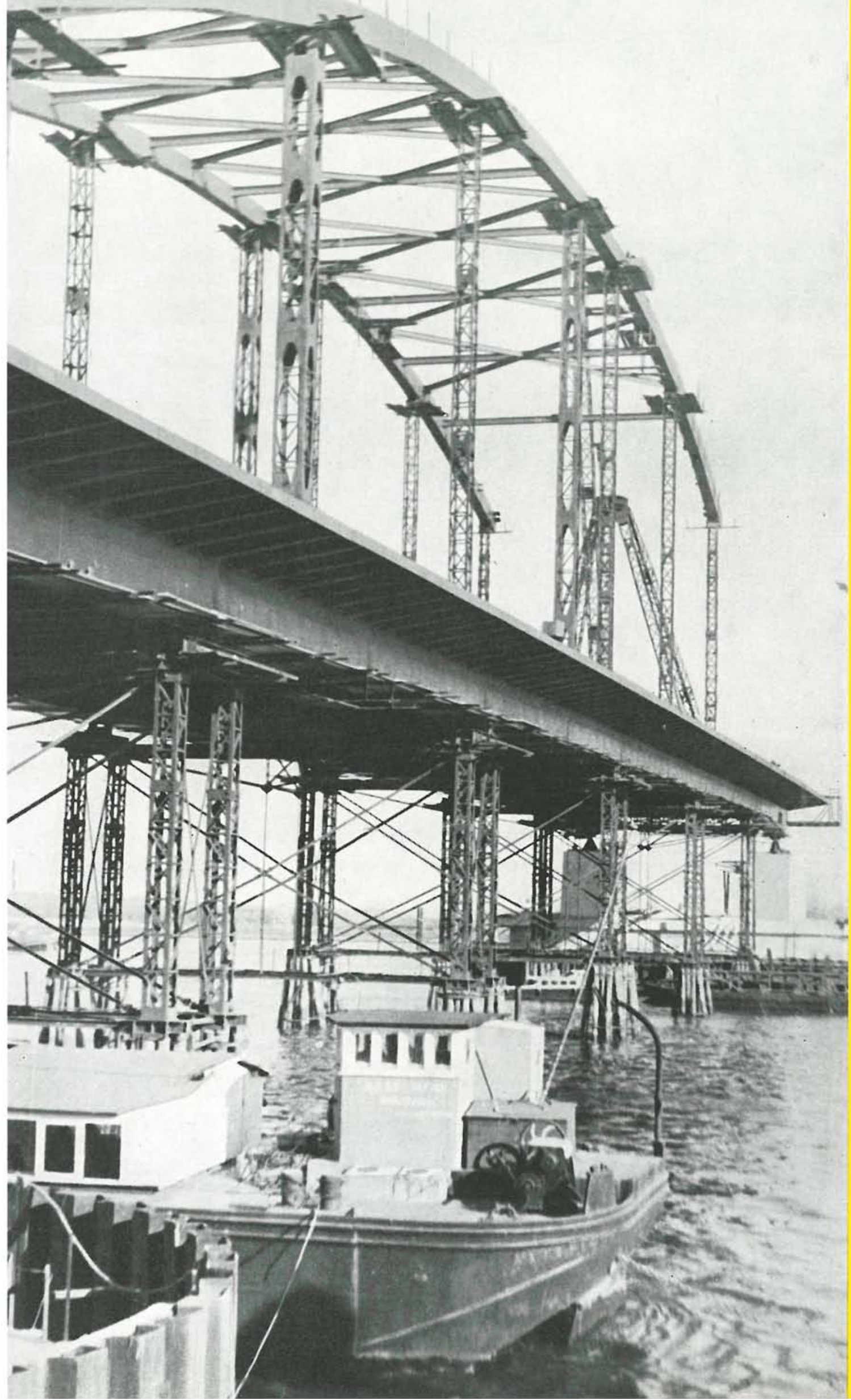

$565 \cdot 19$

\title{
puente sobre el Boven Merwede
}

Información amablemente facilitado por

Prepakt Ibérica, S. A Madrid 


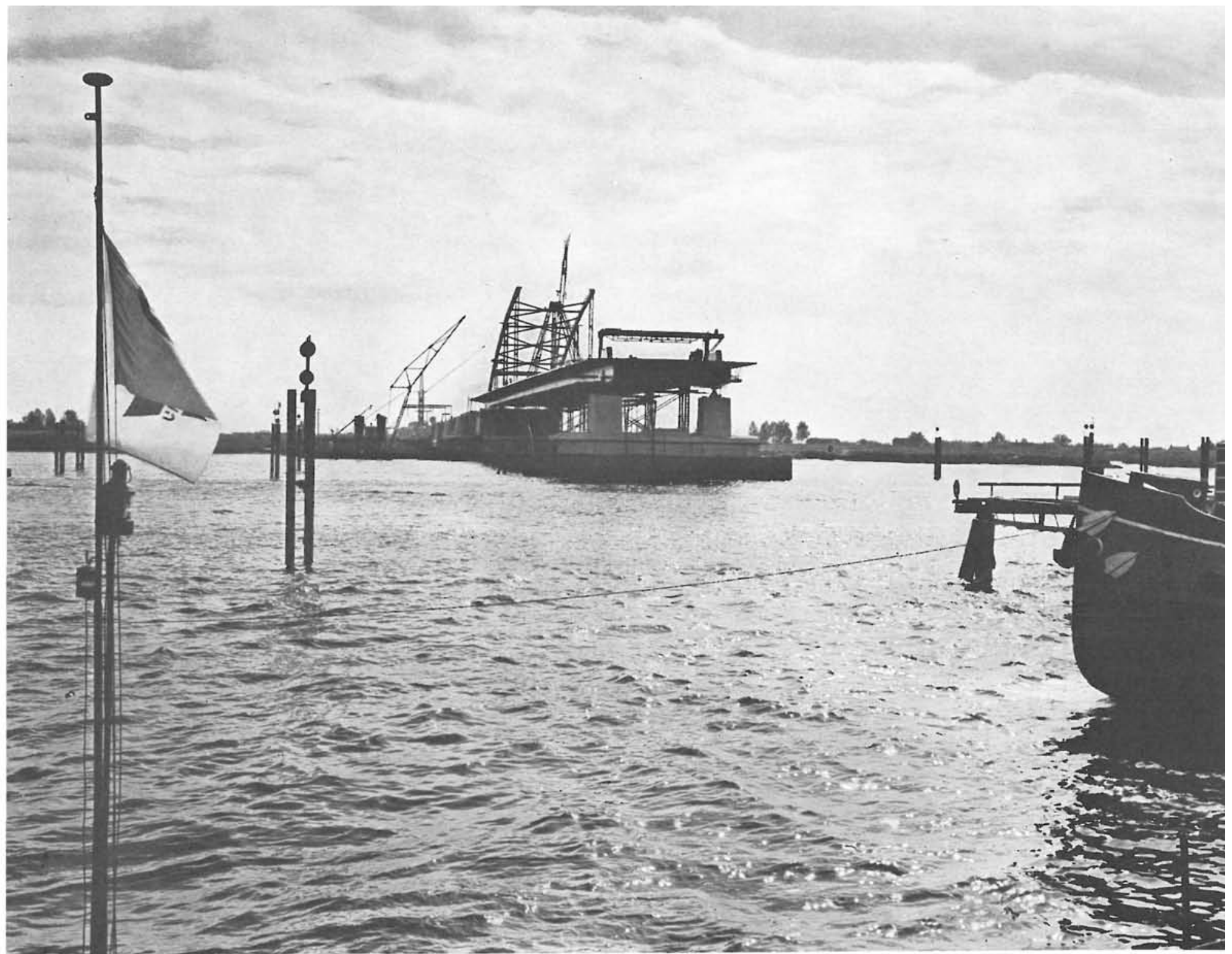

Ataguia de los tramos centrales.

\section{Introducción}

Con objeto de mejorar las comunicaciones por carretera entre el norte de Holanda y el puerto belga de Amberes, ya se había proyectado un nuevo trazado que suprimía muchos pasos a través de ciudades y los transbordadores que cruzaban el Boven-Merwede en las proximidades de Gorinchem.

Empezada la construcción de los estribos del puente que debía suprimir los transbordadores, sobrevino la última guerra mundial y paralizó estas importantes obras.

Terminada la guerra se emprendieron otras obras de reparación de mayor urgencia, pero las obras del puente sobre el Boven-Merwede entraron nuevamente en actividad en el año 1957.

Los transbordadores cruzaron unos 400.000 vehículos y más de 1.600 .000 personas durante el año 1958 , cifras que, por sí mismas, justifican la construcción del puente que es objeto de descripción en este trabajo.

La importancia general de este proyecto la evidencia su inclusión en el gran sistema europeo de carreteras generales. La construcción de este puente y un viaducto situado al norte de Steenenhoek constituyen las obras más caracterizadas de este nuevo trazado. Estas obras, empezadas en mayo del año 1958 y en mayo del 1959, respectivamente, se han ejecutado por la Dirección General de Puentes de Holanda.

\section{Cimientos}

Las pilas que soportan los dos tramos centrales, estribos y paso inferior navegable, se apoyan sobre pilotes de hormigón pretensado, de sección cuadrada de $40 \mathrm{~cm}$ de lado. 
Grupo de pilotes para un soporte.

Tramos de acceso.

Estos elementos se han armado con 12 cables de $14 \mathrm{~mm}$ de diámetro, de acero soldable, $85 \mathrm{~kg} / \mathrm{mm}^{2}$ de resistencia mínima de rotura y $55 \mathrm{~kg} / \mathrm{mm}^{2}$ en el límite elástico. El esfuerzo de pretensado por pilote es de 72 toneladas.

Después de una serie de sondeos de reconocimiento, se llegó a la conclusión de que las profundidades que debían alcanzar los pilotes bajo las pilas variarían de 14 a 19 metros.

El apoyo del mecanismo basculante del paso inferior, los tres correspondientes a los dos arcos y los tres del tramo de acceso sur, todos ellos se han construído por medio de ataguías que, previamente dragado el lugar, se hincaron después. Partiendo del interior de estas ataguías se procedió a la hinca de pilotes.

Terminada la hinca de pilotes se procedió a hormigonar, bajo el agua, una solera que serviría de arriostramiento del tablestacado y, además, de contrapeso, junto con el peso propio del resto del tablestacado, para contrarrestar el empuje de flotación del agua al agotar en el interior del recinto o célula de tablestacas. Convenientemente arriostrada la parte superior del tablestacado se procedió a bombear el agua, cortar los pilotes a la debida altura y seguir el hormigonado de la pila.

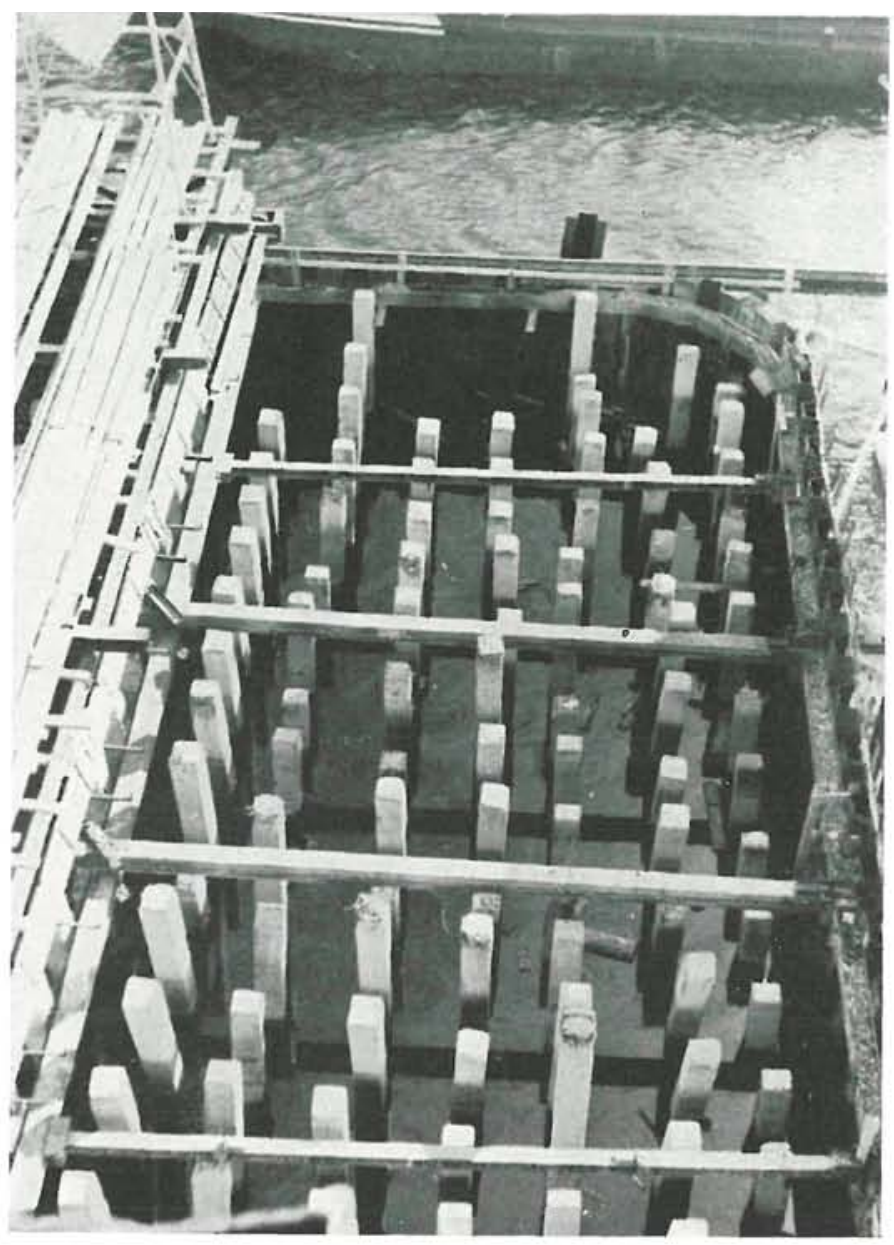

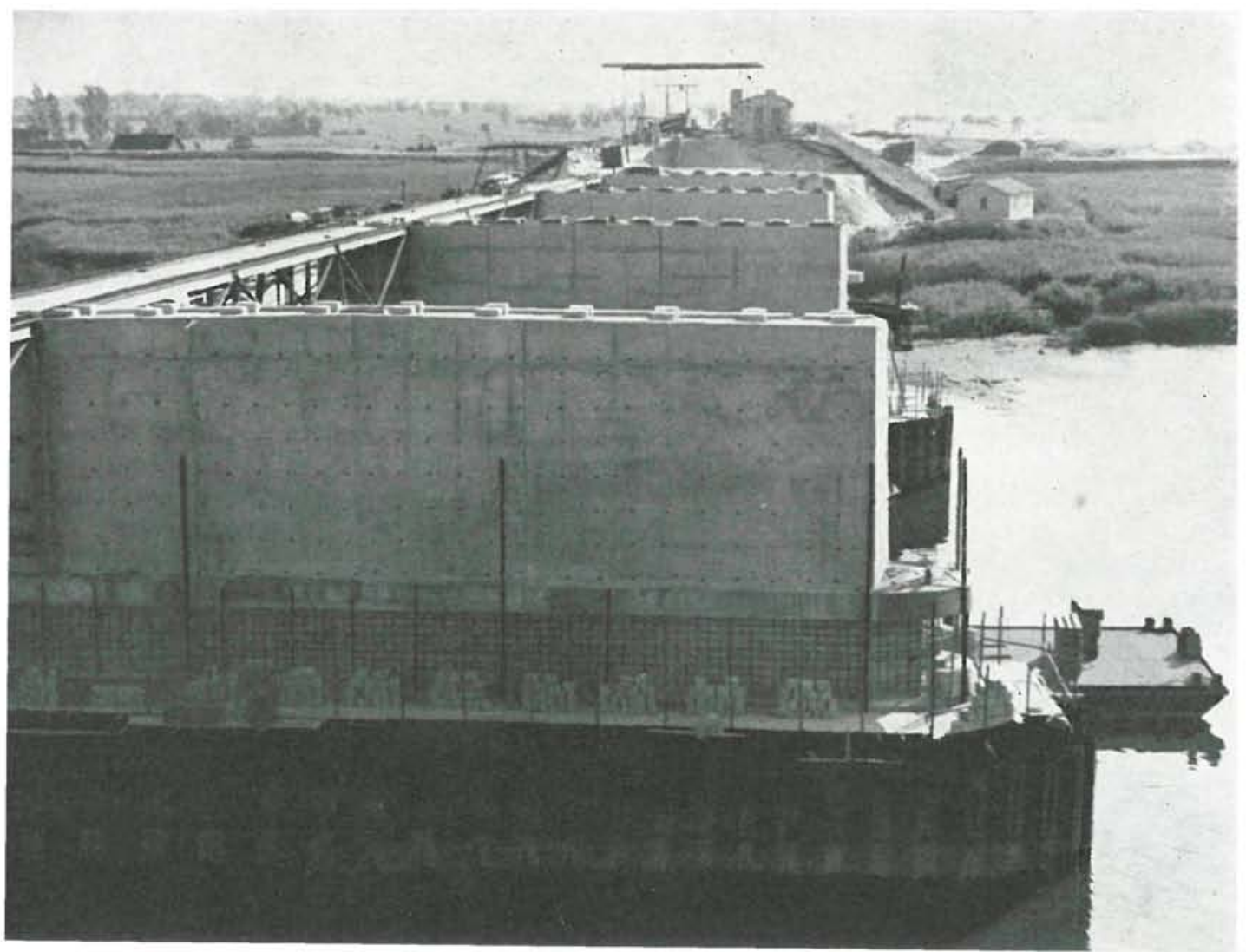



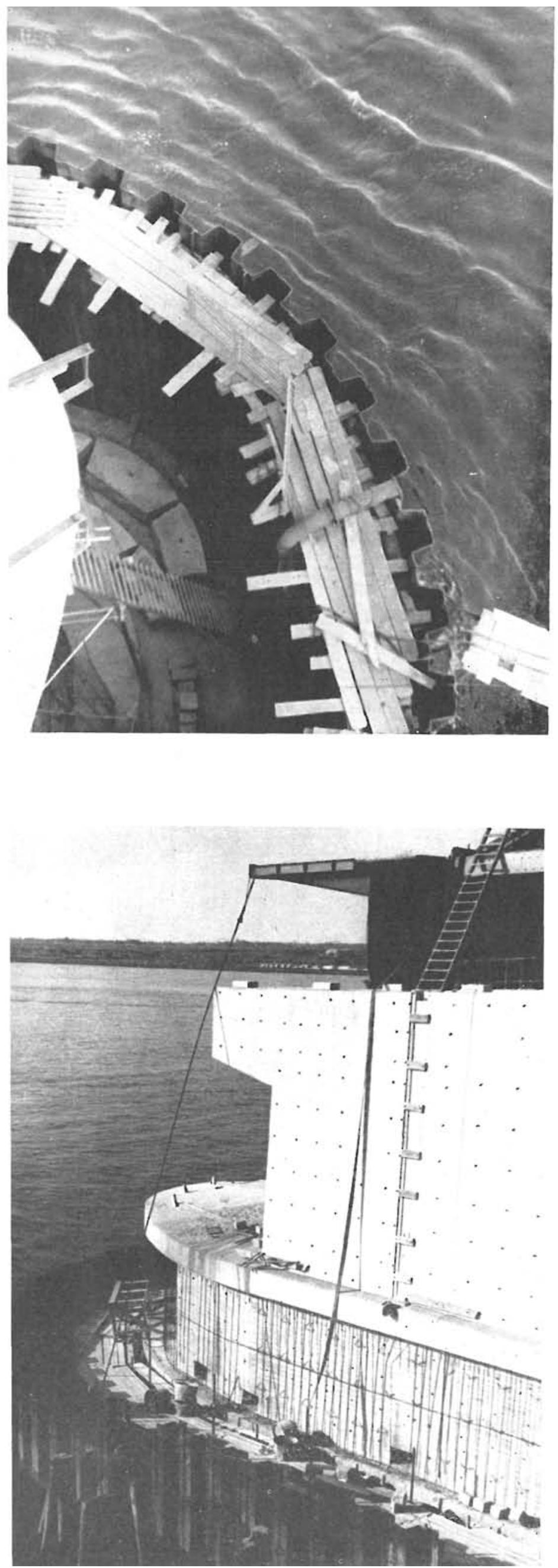

Tablestacado de una ataguia.

Una pila de los tramos centrales.

El espesor de las capas de hormigón colocado bajo el agua es de $2,50 \mathrm{~m}$ en los soportes de los arcos y de $2 \mathrm{~m}$ en el apoyo del mecanismo de basculación y en los tres soportes del acceso sur. Este hormigón se colocó en obra bajo el agua, siguiendo el sistema "Intrusión Prepakt".

Para este tipo de hormigonado se empezó colocando la grava lavada, de $20-100 \mathrm{~mm}$ de extremos granulométricos dimensionales, en el fondo de la ataguía y a la altura que debía tener la capa. Después se inyectó el mortero mediante tubos de $31 \mathrm{~mm}$ de diámetro, espaciados a 2,50 y hasta $3,00 \mathrm{~m}$. La inyección se verificó por medio de bombas que podian inyectar en cuatro tubos simultáneamente. La composición de un metro cúbico de hormigón es:

1.000 litros de grava $20-100 \mathrm{~mm}$ (60\% de materia sólida),

$300 \mathrm{~kg}$ de cemento (de horno alto, clase A),

$3 \mathrm{~kg}$ de Intrusión Aid,

$390 \mathrm{~kg}$ de arena seca (de 1,7 a 2,0 de módulo de finura), $150 \mathrm{~kg}$ de agua,

de cuya composición resultó una relación agua-cemento de 0,50 . A los 21 días, este hormigón tenía una resistencia de $275 \mathrm{~kg} / \mathrm{cm}^{2}$. La gran ventaja de este procedimiento es la rapidez que se puede lograr en la colocación del hormigón, sin que sea posible la segregación y, por tanto, la sedimentación de barros de cemento sobre el hormigón.

Como las pilas de la margen norte se hallan sobre un terreno más elevado, su cimentación se hizo siguiendo los procedimientos convencionales de pozos abiertos, sin que fuera necesario el agotamiento. Las soleras de base sólo tienen $15 \mathrm{~cm}$ de espesor.

Todos los soportes del puente se han recubierto con granito especial, resistente a los efectos de arrastre durante el deshielo.

\section{Instalaciones generales}

Para la construcción de esta importante obra se han instalado talleres de prefabricación de vigas de hormigón pretensado, además de una serie de barracones para atenciones de reparación $y$ conservación de la maquinaria auxiliar, administración y otros servicios anexos a la obra.

En el acceso sur se ha montado un entramado sobre el que circulan una grúa móvil y los camiones de aprovisionamiento de materiales durante la construcción de estos tramos. En la margen norte también se ha instalado una grúa móvil.

Como los aprovisionamientos se verifican por vía fluvial, algunas de las pilas de la margen sur han sido aprovisionadas por barcazas que utilizaban los canales dragados para su navegación.

Se ha previsto un período de 30 meses para la ejecución de este proyecto, lo que nos lleva al otoño del año 1960 para la terminación del puente.

\section{Descripción general de la obra}

El puente para carretera sobre el Boven-Merwede se compone de cuatro partes integrantes, diferenciadas y de mayor importancia. Siguiendo la dirección norte-sur nos encontramos, en primer lugar, con los cuatro tramos de acceso, formados por pórticos de vigas de hormigón pretensado constituyendo cabezal; un paso inferior navegable, de $30 \mathrm{~m}$ de luz, cuyo tablero es basculable para permitir la navegación; dos arcos centrales metálicos, de unos $170 \mathrm{~m}$ de luz, que constituyen la parte más importante de la obra y, ya en la margen sur, otros cuatro tramos, también aporticados, cuyo tablero se forma con vigas pretensadas de hormigón armado. 

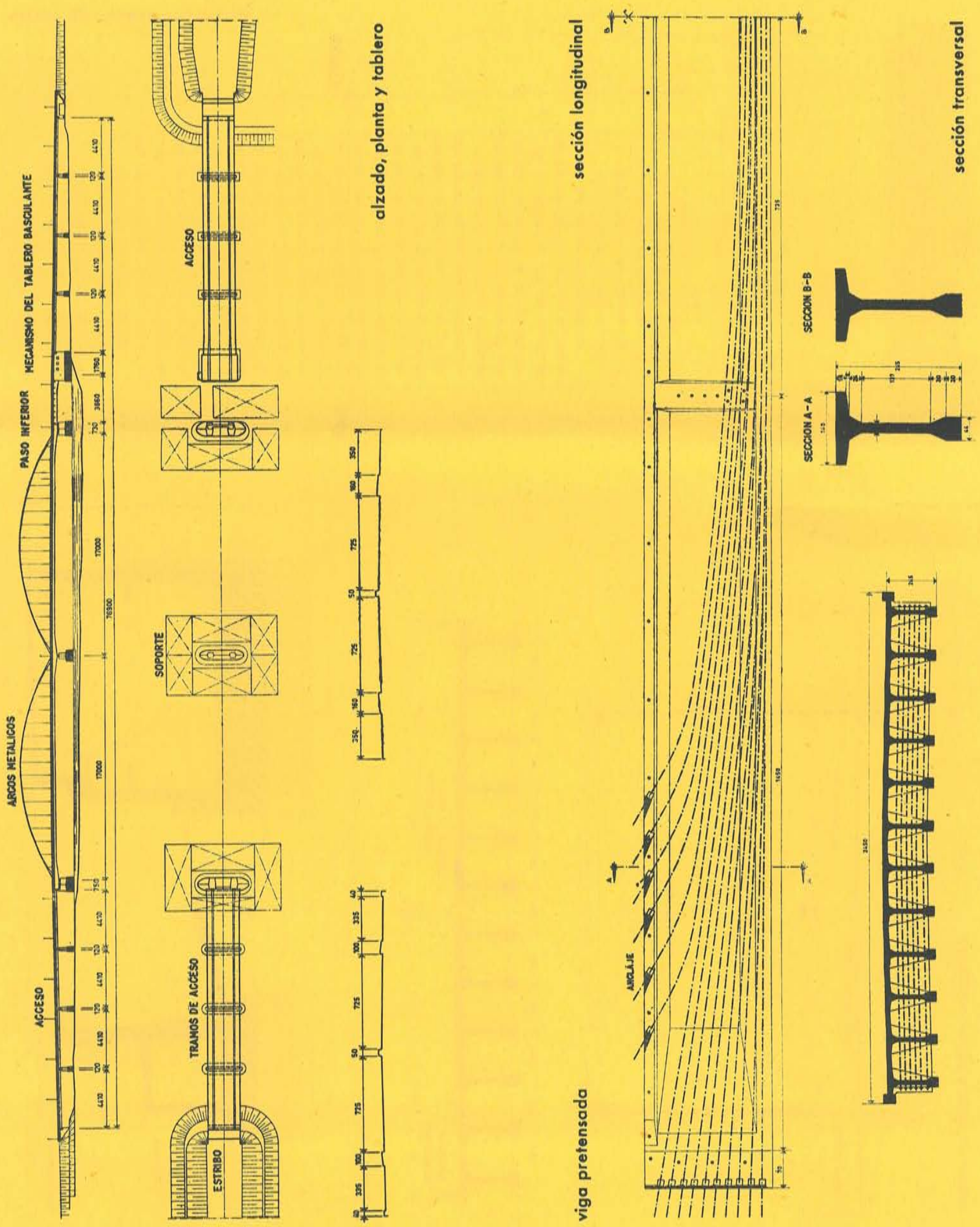


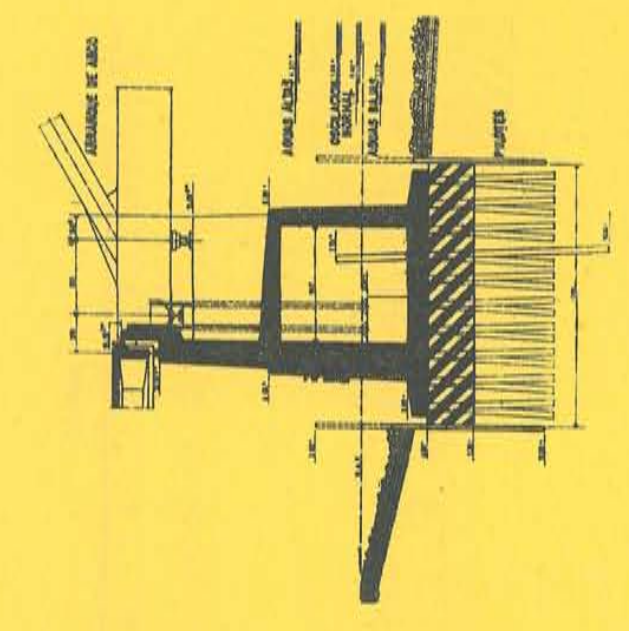

0
$=$
$\vdots$
0
0
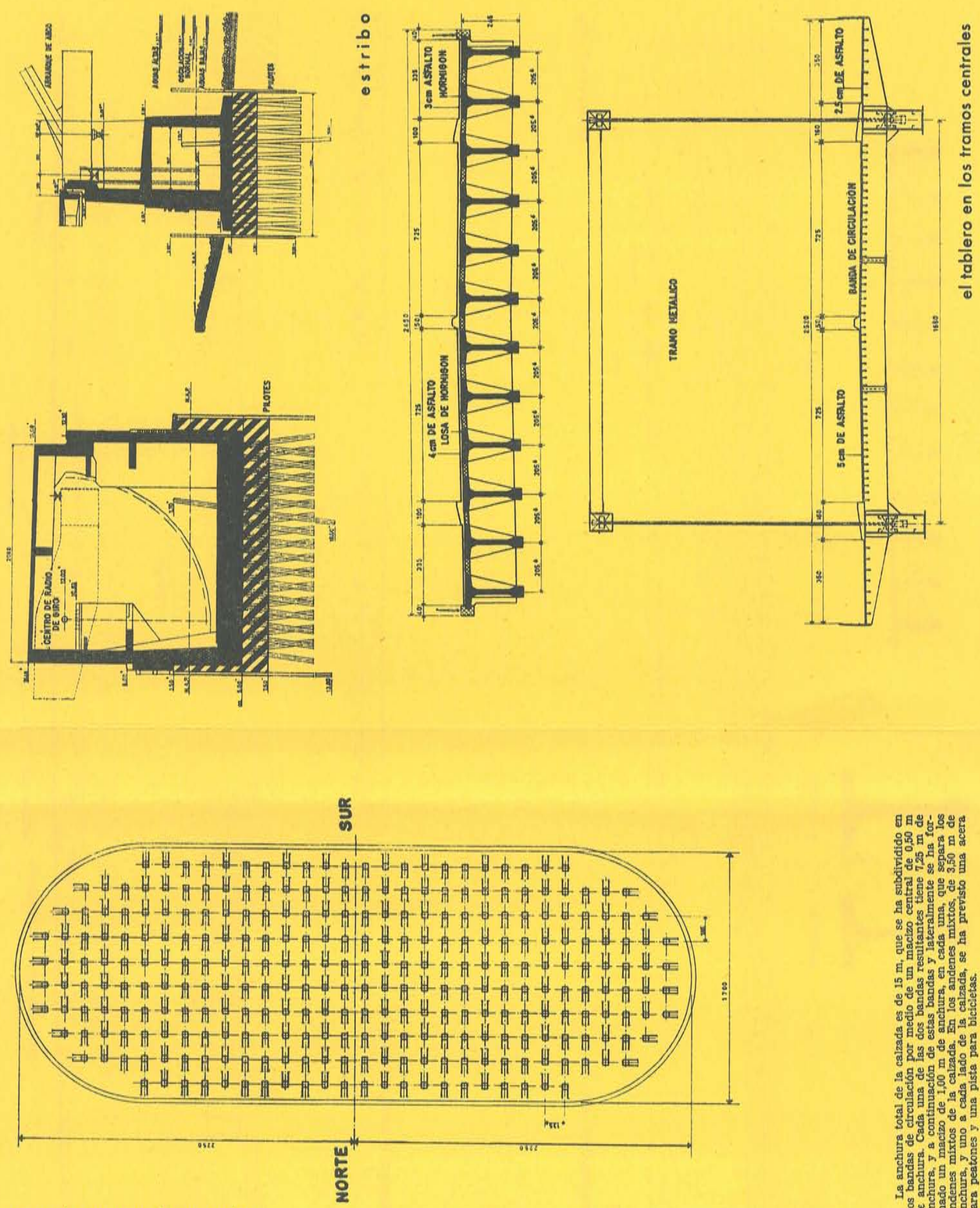

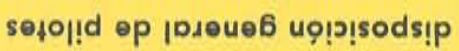

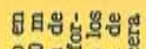

우예 ํํำ

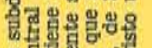

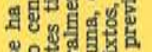

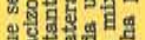

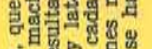
目目

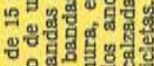

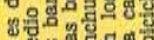
연 สำ

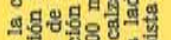

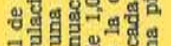
ㅎํ의 s.

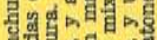

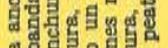

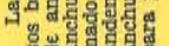



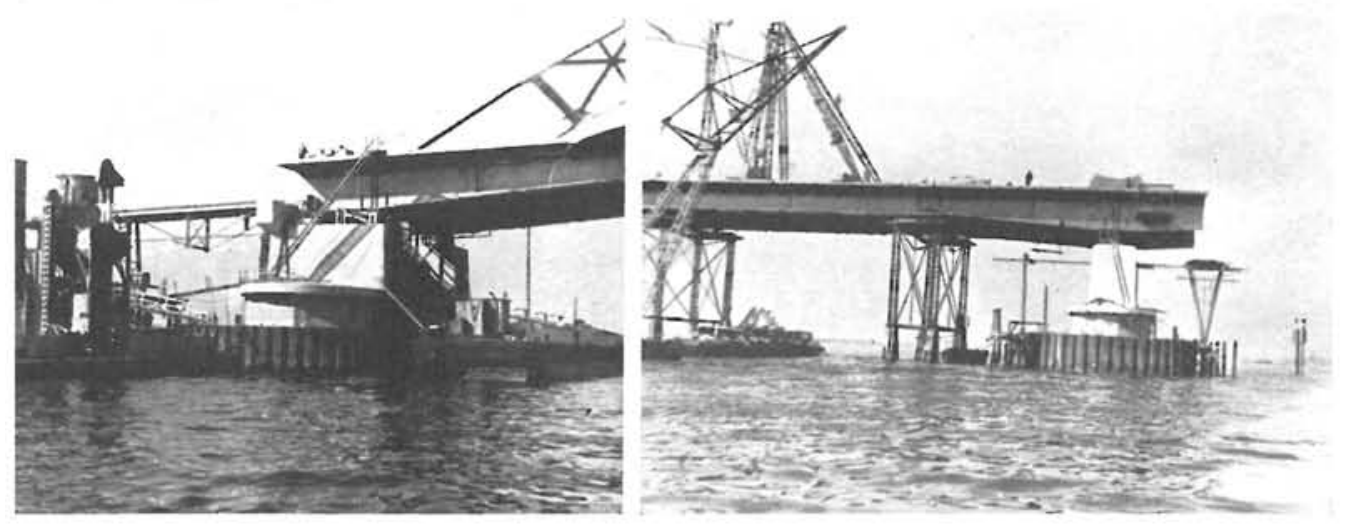

Arranque de un tramo en arco.

Apoyo para los tramos centrales.

\section{Arcos centrales}

El perímetro mojado del río en estiaje será salvado por dos tramos metálicos en arco, de $170 \mathrm{~m}$ de luz aproximadamente. Estos arcos constituyen un entramado metálico rígido, y sirven de suspensión de las vigas maestras que se extienden en forma continua sobre sus tres puntos de apoyo.

Para mejorar las condiciones de rigidez y, a su vez, reducir una parte considerable de acero de la estructura, las vigas longitudinales principales se han fijado a las pilas mediante cables. El efecto de fijación se consigue amarrando cuatro cables por viga a unos $5 \mathrm{~m}$ de los rodillos del apoyo. Cada uno de estos cables tiene una capacidad de 130 toneladas de esfuerzo a tracción, y pasan a las pilas, que sirven para su anclaje, por medio de tubos.

Por economía de acero y peso en los arcos se ha formado el firme de la calzada a base de chapa de acero recubierta con una capa de asfalto fundido, de $5 \mathrm{~cm}$ de espesor. Las péndolas de suspensión del tablero están constituídas por cables de acero de alta calidad y de $74 \mathrm{~mm}$ de diámetro cada uno.

En la construcción de los dos arcos centrales se han empleado unas 3.400 toneladas de acero. En la extremidad norte de estos arcos centrales, el tramo que salva el paso inferior navegable está constituído por dos vigas principales y una serie de vigas transversales que se han cerrado con un firme de madera de especies tropicales.

\section{Tramos de acceso}

Como ya se indicó anteriormente, cada uno de los accesos se compone de cuatro tramos formados por vigas de hormigón pretensado. Cada uno de estos tramos tiene unos $44 \mathrm{~m}$ de luz. Estas vigas se han prefabricado en un taller, montado en obra, utilizando moldes metálicos. Las cabezas de las vigas, en las que van los conos de anclaje de los cables de pretensado, se han prefabricado utilizando también moldes metálicos, para mejorar, en la medida de lo posible, la resistencia a la compresión del hormigón. Como es corriente, el hormigón utilizado en la prefabricación se ha vibrado.

Estribo-pila de un tramo central.

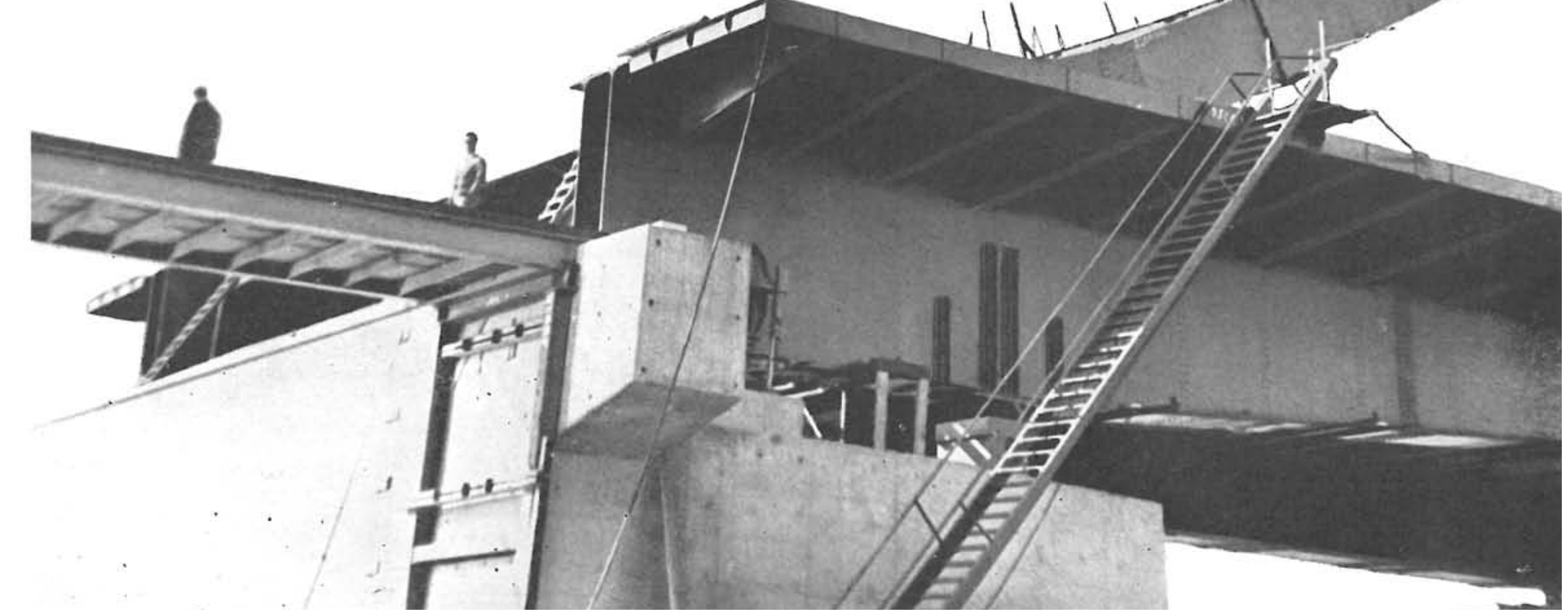




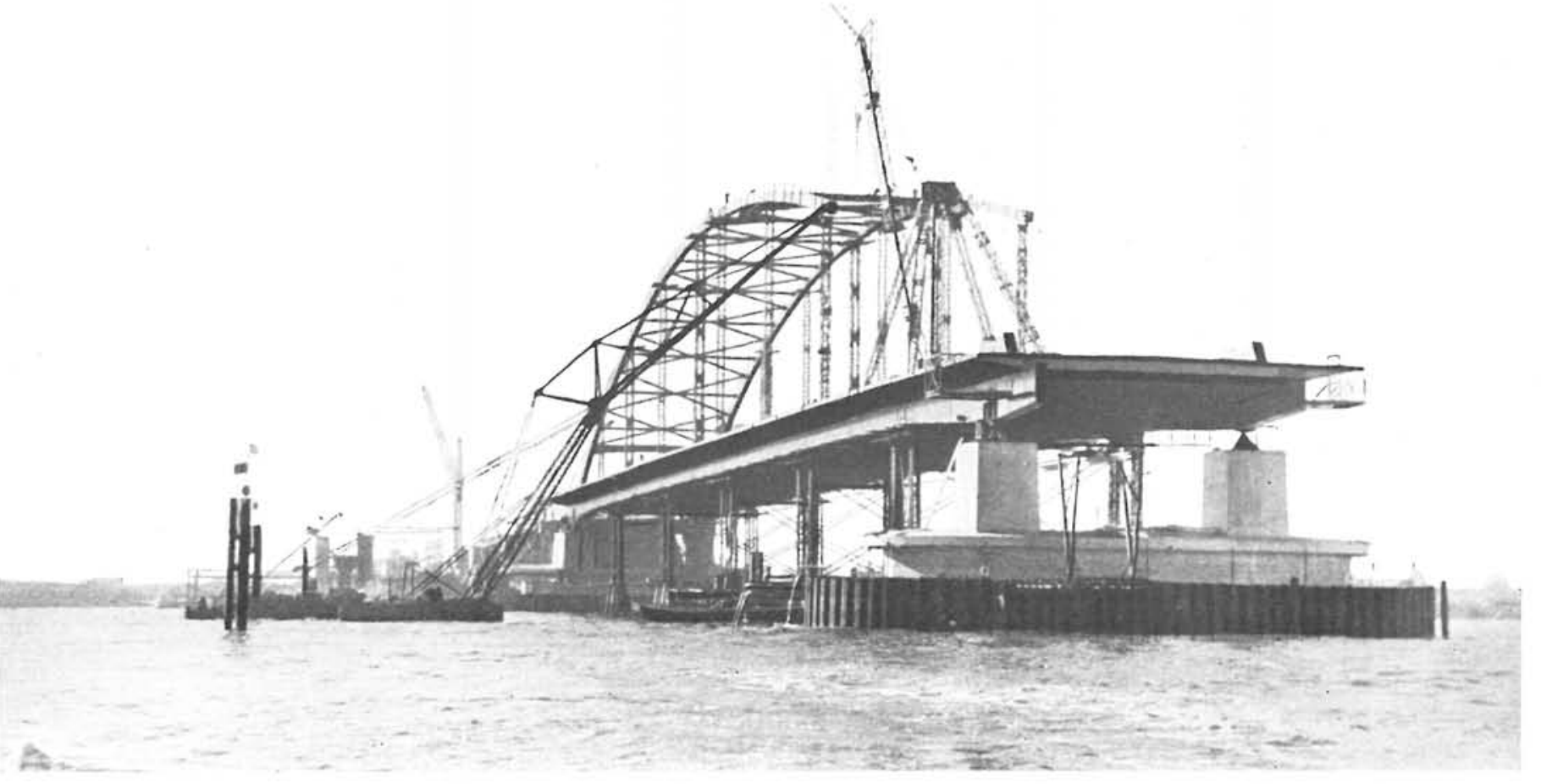

Fotosi J. W. DURRER

Terminado el hormigonado de cada viga se procede a las operaciones de curado valiéndose de un caparazón móvil, colocado alrededor de la viga y que se llena con vapor de agua. En todas las manipulaciones de estas vigas se han empleado procedimientos mecánicos para su transporte y apilamiento, lo que ha permitido terminar rápidamente las 48 vigas que se necesitaban en el acceso sur y transportar después la instalación al acceso norte para la prefabricación de las 48 restantes vigas.

Todos los apoyos de las vigas constan de tres capas de goma vulcanizada formando sandwich entre chapas de acero, y el conjunto va envuelto también con goma. El espesor de estos apoyos es de unos 6 centímetros.

Las armaduras de cada viga están constituídas por 16 cables, de 12 cordones de alambre de 7 mm de diámetro, de acero de alta calidad St 135-150, y según el sistema Freyssinet. Diez de estos cables se extienden de extremo a extremo y 6 de ellos se elevan hacia las alas superiores de la viga. Cada tramo tiene 12 vigas, colocadas a $2,06 \mathrm{~m}$ entre ejes y de $2,45 \mathrm{~m}$ de canto.

El pretensado transversal se ha realizado siguiendo los cables Freyssinet, 57 por tramo, de 12 cordones de alambre de $7 \mathrm{~mm}$. Inmediatamente después de anclar, el esfuerzo remanente es de 50 toneladas en los conos, mientras que en el centro de la viga es de unas 40 toneladas, después de deducir las pérdidas por contracción, deformación lenta, relajación del acero y pérdidas por rozamiento.

\section{El viaducto de Steenenhoek}

Al norte del puente sobre el Boven-Merwede, en Steenenhoek, se ha construído el viaducto. Tiene el mismo nombre y sirve para la unión con el puente del trazado general. Consiste en una serie de pórticos construídos con vigas prefabricadas de hormigón armado. Su longitud es de 570 metros.

El viaducto está soportado por 25 soportes y dos estribos de hormigón armado. Tanto unos como otros se apoyan sobre pilotes de hormigón pretensado de $38 \times 38 \mathrm{~cm}$ de sección y cuyas armaduras son similares a las empleadas en el puente anteriormente descrito.

La calzada se ha dividido en dos bandas de circulación de dirección única, cada una de ellas de $8,25 \mathrm{~m}$ de anchura, y separadas por un macizo central de $1,00 \mathrm{~m}$ de anchura, construído con elementos prefabricados.

Los tramos de esta obra tienen $21,50 \mathrm{~m}$ de luz. Las vigas se han fijado a los soportes de tal forma, que la estructura constituye un sistema estáticamente indeterminado por la interposición de vigas y las losas de unión entre las alas de las cabezas superiores.

Las vigas transversales transmiten los esfuerzos en esta dirección, y los esfuerzos creados por la flexión de momentos negativos sobre los soportes son transmitidos por las losas de unión.

Tanto las vigas como las losas de unión se han prefabricado utilizando moldes metálicos y siguiendo los procedimientos para el pretensado. El pretensado se ha realizado con armaduras obtenidas de varillas ovales de 30 mm de diámetro, de acero St 145-160. La tensión primaria es de unos $110 \mathrm{~kg} / \mathrm{mm}^{2}$, mientras que la final resultante es de $85 \mathrm{~kg} / \mathrm{mm}^{2}$ según las previsiones calculadas. Cada viga lleva 100 varillas, con lo que se conseguirá un esfuerzo total de 250 toneladas por viga.

El viaducto cruza el canal Steenenhoeñ en esviaje, formando un ángulo de $72^{\circ} 30^{\prime}$ y tiene varios pasos inferiores. 